\title{
Conversion of Vertical Banded Gastroplasty to Roux-en-Y Gastric Bypass Results in Restoration of the Positive Effect on Weight Loss and Co-morbidities: Evaluation of 101 Patients
}

\author{
Ruben Schouten, MD; Francois M.H. van Dielen, MD, PhD; Wim G. van \\ Gemert, MD, PhD; Jan Willem M. Greve, MD, PhD
}

Department of General Surgery, University Hospital Maastricht, the Netherlands

Background: Vertical banded gastroplasty (VBG) is a widely used restrictive procedure in bariatric surgery. However, the re-operation rate after this operation is high. In the case of VBG failure, a conversion to Rouxen-Y gastric bypass (RYGBP) is an option. A study was undertaken to evaluate the results of the conversion from VBG to RYGBP.

Methods: 101 patients had conversion from VBG to RYGBP. Patients were separated into 3 groups, based on the indication for conversion: weight regain (group 1), excessive weight loss (group 2) and severe eating difficulties (group 3). Data for the study were collected by retrospective analysis of prospectively recorded data.

Results: Weight regain (group 1) was the reason for conversion in $73.3 \%$ of patients. Staple-line disruption was the most important cause for the weight regain (74.3\%). Excessive weight loss (group 2) affected $14 \%$ of patients and was caused by outlet stenosis in $78.6 \%$ of patients. The remaining $13 \%$ had severe eating difficulties as a result of outlet stenosis (46.1\%), pouch dilatation $(30.8 \%)$ and pouch diverticula (23.1\%). Mean BMI before conversion to RYGBP was 40.5, 22.3 and $29.8 \mathrm{~kg} / \mathrm{m}^{2}$ in group 1,2 and 3, respectively. Minor or major direct postoperative complications were observed in $\mathbf{2 . 0} \%$ to $\mathbf{7 . 0} \%$. Long-term complications were more frequent, and consisted mainly of anastomotic stenosis (22.7\%) and incisional hernia (16.8\%). Follow-up after conversion was achieved in all patients $(100 \%)$, with a mean period of $38 \pm 29$ months. BMI decreased from 40.5 to $30.1 \mathrm{~kg} / \mathrm{m}^{2}$, increased from 22.3 to $25.3 \mathrm{~kg} / \mathrm{m}^{2}$. and decreased slightly from 29.8 to $29.0 \mathrm{~kg} / \mathrm{m}^{2}$ in group 1,2 and 3 , respectively. All patients in group 3 noticed an improvement in eating difficulties.

Correspondence to: R. Schouten MD, Department of General Surgery, University Hospital of Maastricht, P.O. Box 5800, 6202 AZ Maastricht, The Netherlands. Fax. +31 4343 3875473; e-mail: r.schouten@surgery.azm.nl
Conclusion: Complications after conversion from failed VBG to RYGBP are substantial and need to be considered. However, the conversion itself is a successful operation in terms of effect on body weight and treating eating difficulties after VBG.

Key words: Vertical banded gastroplasty, failure, conversion, Roux-en-Y gastric bypass, morbid obesity

\section{Introduction}

Morbid obesity is a rapidly growing problem in western society. In the United States, $2 \%$ of men and $6 \%$ of women are morbidly obese, and have a mortality rate up to 12 times greater compared to normal-weight individuals. ${ }^{1,2}$ In the Netherlands, the prevalence is less disturbing but the incidence of obesity and especially morbid obesity, defined as a body mass index (BMI) of $>40 \mathrm{~kg} / \mathrm{m}^{2}$ or $>35 \mathrm{~kg} / \mathrm{m}^{2}$ with obesity-related co-morbidities, ${ }^{3}$ is rising progressively to $1.5 \%$ of the total population in $2004 .^{4}$

At this moment, surgical therapy is the only treatment option for these patients that results in sufficient long-term weight loss. ${ }^{5}$ Non-surgical approaches, like low energy diets and behavior modification, are not successful in the long-term with respect to maintaining weight loss and decreasing obesity-related co-morbidity. ${ }^{6}$

Gastric restrictive surgery was introduced in the mid-1970s in the form of transverse gastroplasty and has been developed and improved since. ${ }^{7}$ This procedure evolved to vertical banded gastroplasty (VBG) 
as described by Mason and others, and has been performed on thousands of patients worldwide. ${ }^{8-11}$ However, revisional surgery is often necessary after VBG, with reported percentages in the literature of $10 \%$ to $41 \%$, mainly because of stoma stenosis, pouch enlargement and staple-line disruption. ${ }^{12-16}$

In the case of VBG failure, conversion to another bariatric operation is a possibility. According to the available literature, conversion to Roux-en-Y gastric bypass (RYGBP) appears to have good results. ${ }^{17-21}$ The present study was conducted in order to evaluate the mid-term results of the conversion from VBG to RYGBP.

\section{Patients and Methods}

\section{Patients}

Between April 1988 and January 2002, a total of 288 patients underwent a VBG in our clinic. All patients were between age 18 and 60 years at the time of operation and had failed previous non-surgical attempts to lose weight. Patients were considered eligible if the BMI was $>40 \mathrm{~kg} / \mathrm{m}^{2}$ or $>35 \mathrm{~kg} / \mathrm{m}^{2}$ with obesity-related co-morbidities. All patients treated by VBG were followed postoperatively. Between December 1996 and November 2005, a total of 101 patients had a conversion from VBG to RYGBP because of weight regain, excessive weight loss or severe eating difficulties. Thirteen patients from this group (12.9\%) were referred from other hospitals. Failure rate after VBG in patients from our clinic was $30.6 \%$ (88 patients). Patient characteristics are listed in Table 1 . The patient group consisted of 15 males and 86 females with a mean age of $40.0 \pm 8.4$ years. Mean weight and BMI before VBG was 137.0 $\pm 27.5 \mathrm{~kg}$ and $48.4 \pm 7.7 \mathrm{~kg} / \mathrm{m}^{2}$.

Table 1. Patient characteristics

\begin{tabular}{lc}
\hline Variables & Before VBG \\
\hline Patients $(\mathrm{N})$ & 101 \\
$\mathrm{M}: \mathrm{F}$ & $15: 86$ \\
Age (years) & $40.0(26-64) \pm 8.4$ \\
Weight $(\mathrm{kg})$ & $137.0(90.0-229.5) \pm 27.5$ \\
BMl $\left(\mathrm{kg} / \mathrm{m}^{2}\right)$ & $48.4(35.9-74.0) \pm 7.7$
\end{tabular}

\section{Surgical Technique}

The surgical technique of the VBG has previously been described in detail.9,10,17

RYGBP was performed through the old upper midline incision. The operative field was freed by sharp and blunt dissection, and the band was removed. In the case of staple-line disruption, the pouch was created with a diameter of $1 \mathrm{~cm}$ and a length of $5-6 \mathrm{~cm}$. In other cases, the existing staple-line was transected after which the pouch was trimmed by resection of excess gastric tissue with a stapler device (GIA-60, Autosuture, Zeist, the Netherlands). The latter was done to prevent formation of an excluded segment of stomach which can result in a mucocele. In all cases, the gastric pouch was completely disconnected from the excluded stomach. Next, the jejunum was transected 40-60 cm distal to the ligament of Treitz. The staple-line of the long limb was reinforced with a running suture, and brought retrocolic and retrogastric to the gastric pouch. Through a small opening on the antimesenteric side, an end-to-side gastrojejunal anastomosis was created. The Roux-en-Y reconstruction was completed with an end-to-side jejunojejunal anastomosis $60-120 \mathrm{~cm}$ distal to the gastrojejunal anastomosis. To prevent herniation, all mesenteric defects were closed with a nonabsorbable suture. The abdominal wall was closed with a running nonabsorbable suture and the skin with staples. Due to a high anastomotic stenosis rate in patients operated before 2004, the operative technique was modified in that year, where instead of a small anastomosis, calibrated with a charriere 14 nasogastric tube, a wider anastomosis was calibrated with a charriere 32 tube. This widening of the anastomosis was performed in association with placement of a silastic ring of 6-6.5 $\mathrm{cm}$ in diameter $1 \mathrm{~cm}$ proximal to the gastrojejunostomy, as described by Fobi et al. ${ }^{22,23}$ The last 13 patients (12.9\%) were operated according to this technique. Patients received intravenous prophylactic antibiotics and subcutaneous heparin. Vitamin A, B, D and iron supplementation were prescribed postoperatively.

\section{Data Collection}

Patients were seen on a regular basis at the outpatient clinic by the surgeon, nurse practitioner, dietician and psychologist. Necessary data for this study were col- 
lected by retrospective analysis of prospectively recorded data. In order to accomplish a complete database, questionnaires were sent to the patients to collect up-to-date information on body weight, co-morbidities, complications and symptoms. Presence and resolution of obesity-related co-morbodities were quantified by the use and discontinuation postoperatively of medication in the instance of diabetes, hypertension and hypercholesterolemia. Joint problems, asthma, gastroesophageal reflux disease (GERD) and depression were quantified by both history-taking and/or medication. The presence of preoperative sleep apnea syndrome was quantified by sleep studies in all patients, the resolution postoperatively by subjective improvement of sleep and daily drowsiness and the discontinuation of the use of CPAP masks.

Patients were categorized into three groups for analysis based on the indication for conversion: group 1 - weight regain after initially successful weight loss, group 2 - excessive weight loss leading to a BMI $<25$ with malnutrition (low albumin and total protein levels), and group 3 - severe eating difficulties (daily nausea, vomiting or pyrosis, dysphagia while eating and not existing preoperatively, continuous epigastric pain postoperatively not caused by other demonstrable problems except the operation, or daily passage problems with solid food). Despite these eating difficulties, patients from group 3 had an acceptable weight loss postoperatively.

The effect of the conversion on weight loss and co-morbidities was the main interest of the study. Furthermore, data were collected on the time between operations, operating time, hospital stay, perioperative and mid-term complications and reoperations performed during follow-up. All data are reported as mean \pm standard deviation.

\section{Results}

\section{Indications for Conversion}

Patients were categorized into the three groups based on the indication for conversion (Table 2).

\section{Group 1: Weight Regain}

This group consisted of 74 patients (73.3\%) with initially successful weight loss after VBG but weight regain during follow-up. Causes of this weight regain
Table 2. Indication for conversion from VBG to RYGBP

\begin{tabular}{ll}
\hline Indication & Patients (\%) \\
\hline Group 1: weight gain & $74(73.3 \%)$ \\
Group 2: excessive weight loss & $14(13.9 \%)$ \\
Group 3 severe eating / outlet difficulties & $13(12.8 \%)$
\end{tabular}

were mainly staple-line disruption $(74.3 \%)$ and pouch dilatation (9.4\%), defined as increased pouch size on upper GI series compared to the first postoperative GI series but without anastomotic stenosis. The size of the pouch was measured in relation to the vertebrae. Furthermore, four patients (5.4\%) were sweets eaters. Infrequent causes were outlet stenosis (1.4\%), complicated by pouch diverticula and resulting in intake of high caloric liquids, persistent retrosternal pain (1.4\%) caused by anastomotic stenosis and solid food intolerance leading to change of eating habits (high caloric liquids), and a wide outlet of the pouch (1.4\%); in $6.7 \%$ of patients, the cause remained unknown. All causes are summarized in Table 3-A.

\section{Group 2: Excessive Weight Loss}

Fourteen patients (13.9\%) had excessive weight loss after VBG, for which conversion to RYGBP was necessary in order to stabilize weight. The main cause for the excessive weight loss was outlet stenosis $(78.6 \%)$. One patient $(7.1 \%)$ had a pouch dilatation, while in two patients $(14.3 \%)$ the cause was not established (Table 3-B).

\section{Group 3: Severe Eating Difficulties}

Thirteen patients $(12.8 \%)$ developed severe eating difficulties during follow-up after VBG. The most

Table 3-A. Causes of VBG failure

\begin{tabular}{|c|c|c|c|}
\hline \multicolumn{4}{|c|}{ Group 1: weight regain ( $N=74$ ) } \\
\hline Cause & $\begin{array}{l}\text { Patients } \\
\text { (N) }\end{array}$ & $\begin{array}{l}\text { Percentage } \\
\text { (of group) }\end{array}$ & $\begin{array}{c}\text { Percentage } \\
\text { (of total) }\end{array}$ \\
\hline Staple-line disruption & n 55 & $74.3 \%$ & $54.5 \%$ \\
\hline Pouch dilatation & 7 & $9.4 \%$ & $6.9 \%$ \\
\hline Sweets eater & 4 & $5.4 \%$ & $4.0 \%$ \\
\hline Wide outlet & 1 & $1.4 \%$ & $1.0 \%$ \\
\hline Pouch diverticula & 1 & $1.4 \%$ & $1.0 \%$ \\
\hline Pain & 1 & $1.4 \%$ & $1.0 \%$ \\
\hline Unknown & 5 & $6.7 \%$ & $5.0 \%$ \\
\hline
\end{tabular}


Table 3-B. Causes of VBG failure

\begin{tabular}{lccc}
\hline \multicolumn{4}{c}{ Group 2: excessive weight loss ( N = 14 ) } \\
Cause & $\begin{array}{c}\text { Patients } \\
\text { (N) }\end{array}$ & $\begin{array}{c}\text { Percentage } \\
\text { (of group) }\end{array}$ & $\begin{array}{c}\text { Percentage } \\
\text { (of total) }\end{array}$ \\
\hline Outlet stenosis & 11 & $78.6 \%$ & $10.9 \%$ \\
Pouch formation & 1 & $7.1 \%$ & $1.0 \%$ \\
Unknown & 2 & $14.3 \%$ & $2.0 \%$
\end{tabular}

frequent difficulties were passage problems of solid foods $(100 \%)$, daily vomiting $(92.3 \%)$ and pyrosis (76.9\%). Weight loss was successful after VBG in this group, and conversion to RYGBP was performed in order to treat the symptoms. Causes of these severe eating difficulties were outlet stenosis $(46.1 \%)$, pouch dilatation $(30.8 \%)$ and pouch diverticula $(23.1 \%)$ (Table 3-C).

\section{Operation and Hospitalization Details}

Mean time between VBG and conversion to RYGBP was $62 \pm 50$ months for the total group (range 5 to 309 months). There were notable differences between the groups (Table 4). Mean time between the operations was shorter in group 2 with $30 \pm 23$ months compared with $65 \pm 51$ months in group 1 and $76 \pm 50$ months in group 3 .

Mean operating time was $3.7 \pm 0.9$ hours with a

Table 3-C. Causes of VBG failure

\begin{tabular}{lccc}
\hline \multicolumn{4}{c}{ Group 3: severe eating problems ( N = 13 ) } \\
Cause & $\begin{array}{c}\text { Patients } \\
\text { (N) }\end{array}$ & $\begin{array}{c}\text { Percentage } \\
\text { (of group) }\end{array}$ & $\begin{array}{c}\text { Percentage } \\
\text { (of total) }\end{array}$ \\
\hline Outlet stenosis & 6 & $46.1 \%$ & $6.0 \%$ \\
Pouch formation & 4 & $30.8 \%$ & $4.0 \%$ \\
Pouch diverticula & 3 & $23.1 \%$ & $3.0 \%$
\end{tabular}

range from 1.9 to 6.8 hours. There were no significant differences between the groups. Cholecystectomy was performed in 6 patients (5.9\%) during the same operative session. In another 15 patients $(14.9 \%)$, cholecystectomy was performed during follow-up after RYGBP, all for symptomatic gallstones.

Mean hospital stay after RYGBP was 12 days, with a wide range of 3 to 84 days. Patients from group 2 were relatively malnourished before the conversion to RYGBP because of the excessive weight loss, and 5 patients $(36 \%)$ received total parental nutrition for a mean of 10 days prior to surgery. Other patients had already started a high protein diet with vitamin and mineral supplements at home. As a result, the mean hospitalization was significantly longer in group 2 (24 days) compared to group 1 (10 days) and group 3 (8 days). Patients from group $2(\mathrm{~N}=14)$ had varying dietary deficiencies preoperatively: albumin (10), iron (10), total protein (8), magnesium (6), vitamin $\mathrm{B}_{1}(4), \mathrm{B}_{6}(3)$, folic acid (3), zinc (3), copper (1) and vitamin $B_{12}$ (1). The conversion was performed as soon as these deficiencies were corrected.

\section{Complications}

Forty-five patients (44.6\%) did not have any complications. Either direct postoperative and/or long-term complications occurred in 56 patients (55.4\%). More than one complication occurred in 19 patients $(18.8 \%)$.

\section{Mortality.}

Two patients died after conversion from VBG to RYGBP (2.0\%). These two patients had weight regain after initially successful weight loss, for which a cause was not found. Both developed severe sepsis postoperatively, one due to leakage at the gastrojejunostomy and one due to a small bowel laceration probably brought on by release of adhesions.

Table 4. RYGBP: operation details

\begin{tabular}{lcccc}
\hline & Group 1 & Group 2 & Group 3 & Total group \\
\hline Time VBG - RYGBP (months) & $65 \pm 51$ & $30 \pm 23$ & $76 \pm 50$ & $62(5-309) \pm 50$ \\
Operation time (hours) & $3.7 \pm 0.9$ & $3.6 \pm 0.7$ & $3.4 \pm 1.0$ & $3.7(1.9-6.8) \pm 0.9$ \\
Cholecystectomy during RYGBP (N) & 3 & 1 & 2 & $6(5.9 \%)$ \\
Cholecystectomy during follow-up (N) & 12 & 3 & 0 & $15(14.9 \%)$ \\
Hospital stay (days) & 10 & 24 & 8 & $12(3-84)$
\end{tabular}


Major Direct Postoperative Complications.

Anastomotic leakage, treated conservatively or operatively depending on the clinical condition, occurred in $2.0 \%$ and $4.0 \%$ of the patients respectively (Table 5). Intraabdominal abscess and internal hernia also occurred in $2.0 \%$ and $4.0 \%$, respectively. Intraabdominal abscesses were treated by CTguided percutaneous puncture and drainage. Internal herniation was treated during re-laparotomy by closure of mesenterial defects.

\section{Minor Direct Postoperative Complications.}

Wound abscess $(7.0 \%)$, urinary tract infection $(6.0 \%)$, pneumonia $(2.0 \%)$ and wound infection $(2.0 \%)$ were all treated without re-operation by antibiotics or abscess drainage on the surgical ward.

\section{Long-term Complications.}

During follow-up, anastomotic stenosis developed in 23 patients $(22.7 \%)$. In group 2, 64.3\% of the patients had anastomotic stenosis compared to $13.5 \%$ in group 1 and $30.8 \%$ in group 3 . Since the introduction of the larger anastomosis with a silastic ring around the pouch (Fobi-Pouch ${ }^{22,23}$ ), a technique used in the last 13 patients, no more anastomotic stenosis have been observed. All stenoses were treated by endoscopic dilatation. The mean number of endoscopic dilatations was $2 \pm 1$ sessions, with a range of one to four sessions.

An incisional hernia was diagnosed in 17 patients (16.8\%) during follow-up. Patients from group 1 had more incisional hernias (18.9\%) compared to patients from group $2(7.1 \%)$ and $3(15.4 \%)$. All were treated by surgical correction using mesh repair.

\section{Effect on Body Weight}

Follow-up after conversion was achieved in all patients $(100 \%)$, with a mean period of $38 \pm 29$ months. In group 2, the follow-up period was longer with $48 \pm 34$ months, compared to $39 \pm 29$ and $24 \pm$ 20 months for group 1 and 3.

Group 1 had mean weight and BMI before VBG of $139 \pm 28 \mathrm{~kg}$ and $49.6 \pm 8.0 \mathrm{~kg} / \mathrm{m}^{2}$, respectively (Table 6). These patients initially had successful weight loss after VBG. The lowest mean weight and

Table 5. Complications after RYGBP

\begin{tabular}{|c|c|c|c|c|}
\hline Complication & Group $1(\mathrm{~N}=74)$ & Group $2(\mathrm{~N}=14)$ & Group $3(\mathrm{~N}=13)$ & Total $(\mathrm{N}=101)$ \\
\hline Anastomotic stenosis & $10(13.5 \%)$ & $9(64.3 \%)$ & $4(30.8 \%)$ & $23(22.7 \%)$ \\
\hline Anastomotic leakage (operative) & $2(2.7 \%)$ & $2(14.3 \%)$ & 0 & $4(4.0 \%)$ \\
\hline Anastomotic leakage (conservative) & $2(2.7 \%)$ & 0 & 0 & $2(2.0 \%)$ \\
\hline Intraabdominal abscess & $1(1.4 \%)$ & $1(7.1 \%)$ & 0 & $2(2.0 \%)$ \\
\hline Wound abscess & $6(8.1 \%)$ & $1(7.1 \%)$ & 0 & $7(7.0 \%)$ \\
\hline Wound infection & $1(1.4 \%)$ & 0 & $1(7.7 \%)$ & $2(2.0 \%)$ \\
\hline Urinary tract infection & $3(4.1 \%)$ & $1(7.1 \%)$ & $2(15.4 \%)$ & $6(6.0 \%)$ \\
\hline Pneumonia & $2(2.7 \%)$ & 0 & 0 & $2(2.0 \%)$ \\
\hline Incisional hernia & $14(18.9 \%)$ & $1(7.1 \%)$ & $2(15.4 \%)$ & $17(16.8 \%)$ \\
\hline Internal herniation & $1(1.4 \%)$ & $2(14.3 \%)$ & $1(7.7 \%)$ & $4(4.0 \%)$ \\
\hline Death & $2(2.7 \%)$ & 0 & 0 & $2(2.0 \%)$ \\
\hline
\end{tabular}

Table 6 . Weight before VBG, and before and after RYGBP

\begin{tabular}{lcccc}
\hline & Group 1 $(\mathbf{N}=\mathbf{7 4})$ & Group 2 (N=14) & Group 3 (N=13) & Total \\
\hline Follow-up after RYGBP (months) & $39 \pm 29$ & $48+34$ & $24 \pm 20$ & $38 \pm 29$ \\
Weight before VBG $(\mathrm{kg})$ & $139 \pm 28$ & $134 \pm 27$ & $127 \pm 24$ & $137 \pm 27.5$ \\
BMl before VBG $\left(\mathrm{kg} / \mathrm{m}^{2}\right)$ & $49.6 \pm 8.0$ & $45.1 \pm 5.1$ & $44.7 \pm 6.8$ & $48.4 \pm 7.7$ \\
Weight before RYGBP $(\mathrm{kg})$ & $113 \pm 23$ & $69 \pm 19.5$ & $83 \pm 24$ & - \\
BMI before RYGBP $\left(\mathrm{kg} / \mathrm{m}^{2}\right)$ & $40.5 \pm 7.1$ & $22.3 \pm 4.8$ & $29.8 \pm 7.9$ & - \\
Last weight $(\mathrm{kg})$ & $83 \pm 23$ & $75 \pm 15$ & $82 \pm 17$ & - \\
Last BMI $\left(\mathrm{kg} / \mathrm{m}^{2}\right)$ & $30.1 \pm 8.4$ & $25.3 \pm 5.2$ & $29.0 \pm 5.0$
\end{tabular}


BMI during follow-up was $84 \pm 19 \mathrm{~kg}$ and $30.4 \pm$ $6.5 \mathrm{~kg} / \mathrm{m}^{2}$. Patients had weight regain leading to a mean weight and BMI of $113 \pm 23 \mathrm{~kg}$ and $40.5 \pm 7.1$ $\mathrm{kg} / \mathrm{m}^{2}$ before the conversion. RYGBP led to successful weight loss with a mean weight and BMI of $83 \pm 23 \mathrm{~kg}$ and $30.1 \pm 8.4 \mathrm{~kg} / \mathrm{m}^{2}$, comparable to the maximum weight loss after VBG.

Group 2 had a mean weight and BMI before VBG of $134 \pm 27 \mathrm{~kg}$ and $45.1 \pm 5.1 \mathrm{~kg} / \mathrm{m}^{2}$, respectively. This group lost significant weight in a relatively short period. In order to prevent further weight loss and serious malnutrition, conversion to RYGBP was performed when weight and BMI were $69 \pm 15 \mathrm{~kg}$ and $22.3 \pm 4.8 \mathrm{~kg} / \mathrm{m}^{2}$. After a mean follow-up period of 48 months, weight and BMI were increased and stabilized at $75 \pm 15 \mathrm{~kg}$ and $25.3 \pm 5.2 \mathrm{~kg} / \mathrm{m}^{2}$.

Group 3 had mean weight and BMI before VBG of $127 \pm 24 \mathrm{~kg}$ and $44.7 \pm 6.8 \mathrm{~kg} / \mathrm{m}^{2}$, respectively. RYGBP was performed to treat symptoms while weight loss was satisfactory after VBG (mean BMI of $29.8 \pm 7.9 \mathrm{~kg} / \mathrm{m}^{2}$ ). After conversion to RYGBP, weight and BMI remained stable at $82 \pm 17 \mathrm{~kg}$ and $29.0 \pm 5.0 \mathrm{~kg} / \mathrm{m}^{2}$.

\section{Effect on Co-morbidities}

After VBG and before conversion to RYGBP, comorbidities were already decreased because of the overall weight loss (Table 7). For example, diabetes had already resolved in 4 of the 5 patients and hypertension in 10 of the 22 patients. Parallel to the weight loss after conversion to RYGBP, obesityrelated co-morbidities decreased further in group 1. There was a continuous decrease in co-morbidities after the conversion, but numbers are small because of the already substantial decrease after VBG.
Diabetes and sleep apnea syndrome completely resolved after RYGBP, while hypertension, hypercholesterolemia, joint problems, asthmatic complaints, GERD and depression all improved further.

\section{Effect on Patients' Symptoms}

Patients from group 3 were specifically operated in order to treat symptoms caused by complications of VBG while weight loss was already satisfactory. All symptoms consisted of upper abdominal complaints: nausea, vomiting, pyrosis, gastric and eating pain, dysphagia and eating difficulties. The presence of symptoms before and after conversion to RYGBP is described in Table 8. All were significantly improved after the conversion.

\section{Revisional Surgery after Conversion to RYGBP}

Seven patients $(6.9 \%)$ needed revisional surgery after conversion from VBG to RYGBP after a mean period of 32 months. All patients were from group 1. Five patients again developed a significant weight regain after initially successful weight loss. In four patients, three with staple-line disruption initially and one a sweets eater as the indication for conversion, the RYGBP was converted to a distal RYGBP with a common channel of 1-1.5 meters. In one patient with spinal cord injury and permanent immobility, an adjustable gastric band was placed around the gastric pouch in order to produce more weight loss but minimize the chance on diarrhea. One patient developed late internal herniation. During elective re-operation, $20 \mathrm{~cm}$ of jejunum was resected and a new gastrojejunostomy was created. The seventh patient complained of severe eating dif-

Table 7. Co-morbidities before VBG, and before and after RYGBP ( group 1; N=74)

\begin{tabular}{lrrr}
\hline Comorbidity & Before VBG & Before RYGBP & \multicolumn{1}{c}{ After RYGBP } \\
\hline Diabetes & $5(6.8 \%)$ & $1(1.4 \%)$ & $0(0 \%)$ \\
Hypertension & $22(29.7 \%)$ & $12(16.2 \%)$ & $2(2.7 \%)$ \\
Hypercholesterolemia & $5(6.8 \%)$ & $2(2.7 \%)$ & $1(1.4 \%)$ \\
Sleep apnea syndrome & $7(9.5 \%)$ & $2(2.7 \%)$ & $0(0 \%)$ \\
Joint problems & $41(55.4 \%)$ & $30(40.5 \%)$ & $13(17.6 \%)$ \\
Asthmatic complaints & $12(16.2 \%)$ & $7(9.5 \%)$ & $1(1.4 \%)$ \\
GERD & $13(17.6 \%)$ & $15(20.3 \%)$ & $8(10.8 \%)$ \\
Depression & $22(29.7 \%)$ & $20(27.0 \%)$ & $11(14.9 \%)$
\end{tabular}


Table 8. Symptoms before and after RYGBP (group 3; $\mathrm{N}=13$ )

\begin{tabular}{lrl}
\hline Symptoms & Before RYGBP & After RYGBP \\
\hline Nausea & $6(46.2 \%)$ & $1(7.7 \%)$ \\
Vomiting & $12(92.3 \%)$ & $1(7.7 \%)$ \\
Pyrosis & $10(76.9 \%)$ & $2(15.4 \%)$ \\
Gastric pain & $7(53.8 \%)$ & $2(15.4 \%)$ \\
Dysphagia & $3(23.1 \%)$ & $1(7.7 \%)$ \\
Pain (while eating) & $7(53.8 \%)$ & $2(15.4 \%)$ \\
Passage problem & $13(100 \%)$ & $2(15.4 \%)$ \\
& &
\end{tabular}

ficulties caused by anastomotic stenosis. After 3 endoscopic dilatations, the symptoms remained unchanged. During elective re-operation, a thorough adhesiolysis was performed and the anastomosis was disconnected and transected. A new and wider gastrojejunostomy was created. In the last three patients, the indication for conversion from VBG to RYGBP was pouch dilatation in one patient and staple-line disruption in two patients.

\section{Discussion}

After the introduction of the $\mathrm{VBG},{ }^{24}$ thousands of morbidly obese patients have been treated with this restrictive procedure. Long-term follow-up studies of VBG report a variable success rate in terms of maintenance of weight loss. Balsiger et $\mathrm{al}^{25}$ found a maintenance of at least $50 \%$ excess weight loss (\%EWL) 10 years after VBG in only $26 \%$ of the patients, while Sugerman et $\mathrm{al}^{26}$ reported a $\% \mathrm{EWL}$ 3 years after VBG of only $38 \%$. The patients of van Dielen et $\mathrm{al}^{27}$ had a better $\% \mathrm{EWL}$ of $70 \%$ after 1 year but the mean weight slightly increased again after 2 years. This observation of weight regain after initial successful weight loss is also reported by Nilsell et al. ${ }^{28}$ There are, however, reports that show much better results of VBG with weight control in $80 \%$ of patients without revisional surgery. ${ }^{29}$

Besides the variable success on weight loss in the long-term, a number of patients develop symptoms or complications after VBG that require revisional surgery. Well-known postoperative problems are frequent vomiting, GERD, maladaptive eating pattern leading to weight regain ("sweets eaters") and food intolerance caused by the restriction. ${ }^{13,19,23}$ A report from Balsiger et $\mathrm{al}^{30}$ found GERD to rise from $15 \%$ preoperatively to $38 \%$ postoperatively. Furthermore, after a follow-up period of at least 10 years, $30 \%$ of patients had a maladaptive eating pattern while $22 \%$ had more than one vomiting episode per week. ${ }^{25}$

As a result of unsatisfactory weight loss and/or unacceptable side-effects and complications, revisional surgery after VBG is common. The reported incidence is $10 \%$ to $41 \%$, but is strongly dependent on the duration and completeness of follow-up. ${ }^{12-16}$

For revisional surgery after VBG, several options are available. A restoration of VBG (re-VBG) is the first option. However, reports have shown that this restoration is not always successful. Van Gemert et $\mathrm{al}^{17}$ reported that after re-VBG, using a KaplanMeyer analysis, $68 \%$ of the patients needed further revisional surgery because of complications or unsatisfactory weight loss. Other authors have reported similar poor results of re-VBG. ${ }^{18,20,31-34}$

Another option is conversion to adjustable gastric banding (AGB). Taskin et $\mathrm{al}^{35}$ reported 7 patients who underwent this conversion and achieved satisfactory results, comparable with the results after primary AGB. ${ }^{35}$ However, because of the same restrictive nature of the procedure, complications like GERD and maladaptive eating patterns can prevail after the conversion. Additional data about the results of the conversion from VBG to AGB are not yet available.

Results of conversion from VBG to RYGBP are described more frequently. Sugerman et a ${ }^{18}$ reported on 53 patients where \%EWL increased from $36 \%$ to $67 \%$ after the conversion. Results were even better in "sweets eaters"; \%EWL increased from $20 \%$ to $70 \%$ in that patient group. ${ }^{18}$ Cordera et $\mathrm{al}^{19}$ reported a decrease in BMI with $46 \mathrm{~kg} / \mathrm{m}^{2}$ before conversion and $35 \mathrm{~kg} / \mathrm{m}^{2}$ after. Also, co-morbidities diminished and subjective patient satisfaction was $90 \%$. Kfoury et $\mathrm{al}^{20}$ performed a distal RYGBP in 45 patients after failed VBG. Results after a follow-up period of at least 2 years were available for 29 patients and $\%$ EWL was $74 \%$ in this group. ${ }^{20}$ Gonzalez et al ${ }^{21}$ reported a decrease in BMI from $40 \mathrm{~kg} / \mathrm{m}^{2}$ to 32 $\mathrm{kg} / \mathrm{m}^{2}$ at 16 months postoperatively. Based on these literature findings, conversion to RYGBP seems to be the most successful treatment option for failed $\mathrm{VBG}$, in terms of postoperative weight loss. However, our data show that the effect on weight is strongly dependent of the indication for the conver- 
sion. In patients with weight regain after initially successful VBG the mean BMI decreased from 40.5 $\pm 7.1 \mathrm{~kg} / \mathrm{m}^{2}$ to $30.1 \pm 8.4 \mathrm{~kg} / \mathrm{m}^{2}$. In contrast, in patients who experienced excessive weight loss after VBG, a slight increase of BMI was observed, while in patients with acceptable weight loss but severe eating difficulties, the BMI remained stable. The latter group underwent the conversion specifically to treat symptoms caused by failed VBG. In the study by Sugerman et al, ${ }^{18}$ the conversion led to relief of symptoms in 23 patients with intractable vomiting or GERD.${ }^{18}$ In the study by Kfoury et al, ${ }^{20} 10$ patients were included with symptoms of GERD; conversion led to a reduction of symptoms in all patients. Balsiger et $\mathrm{a}^{25}$ performed 25 conversions on patients with severe GERD after VBG. At follow-up after 37 months, all patients were free of symptoms. ${ }^{25}$ The results from our study support these literature findings: in group 3, all patients had severe eating difficulties after VBG along with a range of GI complaints. All symptoms significantly decreased after the conversion.

Other important aspects of revisional bariatric surgery are early and long-term morbidity and mortality, which tend to be higher than after primary bariatric surgery. ${ }^{21}$ Reported postoperative mortality after revisional bariatric surgery is $0-2 \% .^{20,31-34,36,37}$ The overall morbidity rate is $12 \%$ to $41 \%$ and strongly dependent on the completeness and duration of follow-up. ${ }^{20,31-34,36,37}$ In the present study, follow-up was $100 \%$ with a mean duration of 38 months. A low rate of perioperative complications was found ( $2 \%$ to $7 \%$ ), but the long-term complications of anastomotic stenosis and incisional hernia occurred in $22.7 \%$ and $16.8 \%$, respectively. This high incidence of long-term complications is, however, within the range of literature findings where anastomotic stenosis is observed in $4 \%$ to $38 \%$ and incisional hernia in $2 \%$ to $20 \%$. $^{12,17-19,21,25}$

The number of hernias could decrease if the conversion from VBG to RYGBP is performed by laparoscopy. Gagner et $\mathrm{al}^{38}$ performed 24 laparoscopic gastric bypasses as a revisional procedure after failed bariatric surgery; 12 patients in this group had failed VBG. Results showed longer operation time but shorter hospital stay and a morbidity rate of $22 \%$. Secondary revisional surgery was necessary in $14.8 \%$. Reports by McCormick et $\mathrm{al}^{39}$ and de Csepel et $\mathrm{al}^{40}$ support these findings although their patient groups were small $(\mathrm{N}=5$ and $\mathrm{N}=7)$. Future studies will have to discern whether laparoscopic revisional surgery after failed VBG is comparable to open revisional procedures in terms of results, safety and feasibility.

In conclusion, revisional bariatric surgery has a high risk of complications and this has to be considered by the surgical team before re-operation. Conversion from failed VBG to RYGBP is generally a successful operation. Results are strongly dependent of the indication for conversion, but the desired effect on weight and symptoms is achieved.

\section{References}

1. Martin LF, Hunter SM, Lauve RM et al. Severe obesity: expensive to society, frustrating to treat, but important to confront. South Med J 1995; 88: 895-902.

2. Drenick EJ. Definition and health consequences of morbid obesity. Surg Clin North Am 1979; 59: 963-76.

3. National Institutes of Health. The practical guide: identification, evaluation and treatment of overweight and obesity in adults. Bethesda, MD: National Institutes of Health, National Heart, Lung, and Blood Institute, and North American Association for the Study of Obesity, 2000. NIH publication number 00-4084.

4. Kemper HCG, Stasse-Wolthuis M, Bosman W. The prevention and treatment of overweight and obesity. Summary of the advisory report by the Health Council of the Netherlands. Neth J of Med 2004; 62: 10-7.

5. Fisher BL, Schauer P. Medical and surgical options in the treatment of severe obesity. Am J Surg 2002; 184: 9S-16S.

6. Bjorntorp P. Results of conservative therapy of obesity: correlation with adipose tissue morphology. Am J Clin Nutr 1980; 33: 370-5.

7. Printen KJ, Mason EE. Gastric surgery for relief of morbid obesity. Arch Surg 1973; 106: 428-31.

8. Gomez CA. Gastroplasty in the surgical treatment of morbid obesity. Am J Clin Nutr 1980; 33: 406-15.

9. Mason EE, Doherty C, Cullen JJ. Vertical gastroplasty: evaluation of vertical banded gastroplasty. World J Surg 1998; 22: 919-24.

10. Eckhout GV, Willbanks OL, Moore JT. Vertical ring gastroplasty for morbid obesity: five year experience with 1463 patients. Am J Surg 1981; 141: 343-9.

11. Deitel M, Shikora SA. The development of the surgical treatment of morbid obesity. J Am Coll Nutr 2002; 21: 365-71. 
12. Maclean LD, Rhode BM, Forse RA. Late results of vertical banded gastroplasty for morbid obesity and super obesity. Surgery 1990; 107: 20-7.

13. Arribas del Amo D, Martinez-Diaz M, Elia Guedea M et al. Vertical banded gastroplasty: is it a durable operation for morbid obesity? Obes Surg 2004; 4: 536-8.

14. Naslund E, Backman L, Granstrom L et al. Seven year results of vertical banded gastroplasty for morbid obesity. Eur J Surg 1997; 163: 281-6.

15. Hall JC, Watts JM, O’Brien PE et al. Gastric surgery for morbid obesity. The Adelaide study. Ann Surg 1990; 211: 419-7.

16. Gemert van WG, Greve JWM, Soeters PB. Long-term results of vertical banded gastroplasty: Marlex versus Dacron banding. Obes Surg 1997; 7: 128-35.

17. Gemert van WG, Wersch MM, Greve JWM et al. Revisional surgery after failed vertical banded gastroplasty: restoration of vertical banded gastroplasty or conversion to gastric bypass. Obes Surg 1997; 7: 1-8.

18. Sugerman HJ, Kellum JM, DeMaria EJ et al. Conversion of failed or complicated vertical banded gastroplasty to gastric bypass in morbid obesity. Am J Surg 1996; 171: 263-9.

19. Cordera F, Mai JL, Thompson GB et al. Unsatisfactory weight loss after vertical banded gastroplasty : is conversion to Roux-en-y gastric bypass successful? Surgery 2004; 136: 731-7.

20. Kfoury E, Vanguiri A. Distal Roux-en-y gastric bypass conversion operation for failed vertical banded gastroplasty. Obes Surg 1993; 3: 41-3.

21. Gonzalez R, Gallagher SF, Haines K et al. Operative technique for converting a failed vertical banded gastroplasty to Roux-en-y gastric bypass. J Am Coll Surg 2005; 201: 366-74.

22. Fobi MA, Lee H. The surgical technique of the FobiPouch operation for obesity. Obes Surg 1998; 8: 283-8.

23. Fobi MAL, Lee H, Felahy B et al. Choosing an operation for weight control, and the transected banded gastric bypass. Obes Surg 2005; 15: 114-21.

24. Mason EE. Vertical banded gastroplasty for obesity. Arch Surg 1982; 117: 701-6.

25. Balsiger BM, Poggio JL, Mai J et al. Ten and more years after vertical banded gastroplasty as primary operation for morbid obesity. J Gastrointest Surg 2000; 4: 598-605.

26. Sugerman HJ, Starkey JV, Birkenhauer R. A randomized prospective trial of gastric bypass versus vertical banded gastroplasty for morbid obesity and their effects on sweets versus non-sweets eaters. Ann Surg
1987; 205: 613-24.

27. Dielen FMH van, Soeters PB, Brauw LM de et al. Laparoscopic adjustable gastric banding versus open vertical banded gastroplasty. A prospective randomized trial. Obes Surg 2005; 15: 1292-8.

28. Nilsell K, Thorne A, Sjostedt S et al. Prospective randomized comparison of adjustable gastric banding and vertical banded gastroplasty for morbid obesity. Eur J Surg 2001; 167: 504-9.

29. Mason EE. Gastric surgery for morbid obesity. Surg Clin North Am 1992; 72: 501-13.

30. Balsiger BM, Murr MM, Mai $J$ et al. Gastroesophageal reflux after intact vertical banded gastroplasty: correction by conversion to Roux-en-y gastric bypass. J Gastrointest Surg 2000; 4: 276-81.

31. Sugerman HJ, Wolper JL. Failed gastroplasty for morbid obesity. Revised gastroplasty versus Roux-y gastric bypass. Am J Surg 1984; 148: 331-6.

32. Benotti PN, Forse RA. Safety and long-term efficacy of revisional surgery in severe obesity. Am J Surg 1996; 172: 232-5.

33. Linner JH, Drew RL. Reoperative surgery - indications, efficacy, and long-term follow-up. Am J Clin Nutr 1992; 55: 606S-610S.

34. Behrns KE, Smith CD, Kelly KA et al. Reoperative bariatric surgery. Lessons learned to improve patient selection and results. Ann Surg 1993; 218: 646-53.

35. Taskin $\mathrm{M}$, Zengin $\mathrm{K}$, Unal $\mathrm{E}$ et al. Conversion of failed vertical banded gastroplasty to open adjustable gastric banding. Obes Surg 2001; 11: 731-4.

36. Yale CE. Conversion surgery for morbid obesity: complications and long-term weight control. Surgery 1989; 106: 474-80.

37. Cates JA, Drenick EJ, Abedin MZ et al. Reoperative surgery for the morbidly obese. A university experience. Arch Surg 1990; 125: 1400-3.

38. Gagner M, Gentileschi P, Csepel J de. Laparoscopic reoperative bariatric surgery: experience from 27 consecutive patients. Obes Surg 2002: 12: 254-60.

39. McCormick JT, Papasavas PK, Caushaj PF et al. Laparoscopic revision of failed open bariatric procedures. Surg Endosc 2003; 17: 413-5.

40. Csepel J de, Nahouraii R, Gagner M. Laparoscopic gastric bypass as a reoperative bariatric surgery for failed open restrictive procedures. Surg Endosc 2001; 15: 393-7.

(Received October 3, 2006; accepted November 28, 2006) 